Article

\title{
Experiencing the Unprecedented COVID-19 Lockdown: Abu Dhabi Older Adults' Challenges and Concerns
}

\author{
Masood A. Badri ${ }^{1,2, *}$, Mugheer A. Alkhaili ${ }^{1}$, Hamad Aldhaheri ${ }^{1}$, Guang Yang ${ }^{1}$, Muna Albahar ${ }^{1,2}$, \\ Asma Alrashdi ${ }^{1}$, Bushra Almulla ${ }^{1}$ and Layla Alhyas ${ }^{1}$ \\ 1 Department of Community Development, Ministries Complex, Abu Dhabi CFJ7+2P, United Arab Emirates; \\ Mugheer@addcd.gov.ae (M.A.A.); Hamad.aldhaheri@addcd.gov.ae (H.A.); Guang.yang@addcd.gov.ae (G.Y.); \\ muna.albahar@addcd.gov.ae (M.A.); Asma.alrashdi@addcd.gov.ae (A.A.); \\ Bushra.almulla@addcd.gov.ae (B.A.); Layla.Alhyas@addcd.gov.ae (L.A.) \\ 2 Department of Business Administration, United Arab Emirates University, \\ Abu Dhabi 6M2H+44, United Arab Emirates \\ * Correspondence: masood@uaeu.ac.ae or masood.badri@addcd.gov.ae
}

Citation: Badri, M.A.; Alkhaili, M.A.; Aldhaheri, H.; Yang, G.; Albahar, M.; Alrashdi, A.; Almulla, B.; Alhyas, L. Experiencing the Unprecedented COVID-19 Lockdown: Abu Dhabi Older Adults' Challenges and Concerns. Int. J. Environ. Res. Public Health 2021, 18, 13427. https:// doi.org/10.3390/ijerph182413427

Received: 15 November 2021 Accepted: 14 December 2021 Published: 20 December 2021

Publisher's Note: MDPI stays neutral with regard to jurisdictional claims in published maps and institutional affiliations.

Copyright: (C) 2021 by the authors. Licensee MDPI, Basel, Switzerland. This article is an open access article distributed under the terms and conditions of the Creative Commons Attribution (CC BY) license (https:// creativecommons.org/licenses/by/ $4.0 /)$.

\begin{abstract}
This study focused on older adults (60+ years old) of both genders in Abu Dhabi during the COVID-19 pandemic before vaccines were made available (age ranged from 60 years to 75 years). They faced more strict rules of movement restriction and isolation that might have resulted in certain psychological feelings and social reactions. The main objective was to understand Abu Dhabi older adults' psychological feelings during the pandemic and to identify their main concerns and challenges considering the various COVID-19-related policies and restrictions. The psychological feelings focused on fear, loneliness, sadness, irritability, emotional exhaustion, depressive symptoms, sleeping disorders, overeating, and excessive screen use. The objectives also included the changes in the psychological feelings concerning time. Other objectives covered better understanding the differences in (some activities) compared to the other age categories. Data were gathered through an online survey of community members from February to July 2020 as part of government initiatives (Department of Community Development). Responses were collected from 574 older adults in Abu Dhabi (60.1\% male and 39.9\% female). The analysis mainly used descriptive analysis, $t$-tests, analysis of variance (ANOVA), and simple trend analysis. For all tests, a $p$-value less than 0.05 was used for significance. The results pointed to the significant rise in feelings related to excessive screen use, fear, loneliness, and stress. The most significant concerns were related to more restrictions being imposed and not being able to see the grandchildren. The impact of new technologies on their quality of life was significantly reflected by respondents. The influence of the pandemic on older adults' health and weight was also investigated. Analysis of variance, $t$-tests, and regression analysis with relevant tests were employed. The relevant results showed that some negative psychological feelings were common among older adults during the pandemic. However, the psychological feelings did not portray significant changes with time, except for sleeping disorders and overeating. Overall, older adults scored significantly different from other age groups on many challenges, concerns, and views regarding new technologies during the pandemic. No significant differences were observed regarding gender and marital status for the challenges and concerns. The research summarizes some policy guidance while noting some limitations of this study and future research directions.
\end{abstract}

Keywords: older adults; COVID-19; social isolation; technological challenges; Abu Dhabi

\section{Introduction}

The World Health Organization (WHO) has identified older adults as especially vulnerable to the novel coronavirus outbreak [1]. Moreover, the COVID-19 virus has created complications, showing more fatal implications among older adults [2]. Meanwhile, the United Nations in May 2020 published a report warning that the COVID-19 pandemic is causing untold fear and suffering for older people across the world [3]. As the virus 
spreads rapidly and health and social protection systems get overwhelmed, older people may increasingly face vulnerability, abuse, and neglect, which should become the focus of policy considerations. Moreover, mortality data from the Oxford COVID-19 Evidence Service [4] indicated a risk of mortality of $3.6 \%$ for people in their $60 \mathrm{~s}$. The data also reported that the percentage increases to $8.0 \%$ and $14.8 \%$ for people in their 70 s and $80 \mathrm{~s}$, respectively.

Most countries issued regulations that encouraged people to stay at home and avoid contact with other people, possibly for an extended time, to shield older adults. There were also enforced lockdowns and curfews. Therefore, the global recommendation for the older population has stressed the issue of social isolation [5,6]. In its more general context, social isolation may include avoiding social contact with family members and friends, social distancing, and organizing the delivery of essential goods and items such as groceries and medications.

The first case of COVID-19 in the UAE was recorded on 29 January 2020 [7]. The UAE was one of the early countries to record confirmed cases. As a result, the UAE government organized an aggressive vaccination program. Such a dynamic vaccination program has effectively controlled the pandemic, as the number of COVID-19 infections fell by $62 \%$ from January 2021 to August 2021. New infections reported in the UAE followed a downward trend for more than two weeks since early August. To keep the pandemic at bay, the government extended the vaccination to all, as it began to provide a booster dose for specific groups as needed [8].

The government issued policies and rules concerning older adults during the COVID19 pandemic as it progressed [8,9]. The rules and policies covered many aspects of everyday living, including, but not limited to, isolation, limits of family visits, and maintaining required distances at home. The recommended COVID-19 prevention protocol and rules also highlighted the necessity to avoid certain conventional social behaviors such as shaking hands, embracing, and kissing [10,11]. In addition, the rules prohibited older adults from going to public places, shopping centers, worship places, and other public gatherings [12]. The UAE government also warned about social distancing through various communication channels, i.e., broadcasts, TV announcements, newspapers, and social media. Acknowledging that social distancing may aggravate loneliness among older people, the messages had a positive and promising tone that conforming to such rules will increase the chances to end the pandemic sooner [13].

In the Emirate of Abu Dhabi, as part of its efforts to improve the health level of older adults, the Family Development Foundation (FDF) implemented several initiatives to control and minimize the spread of COVID-19 [14]. First, in cooperation with the Department of Health, the FDF focused on campaigns of 'Educating Senior Citizens and Residents' in various regions of $\mathrm{Abu}$ Dhabi, with the ultimate goal to 'increase their health awareness levels and enable them to adopt the preventive precautionary measures that contribute to maintaining their health and safety.' As a step further, family members, friends, local charities, voluntary organizations, and community organizations were encouraged to develop comprehensive networks to ensure each older person has some meaningful social contact to support [15]. Through such organized and comprehensive approaches, social charities, organizations, and healthcare providers could work together to support older people through this period of social isolation and loneliness. The government also communicated with older adults in Abu Dhabi to inform them that they were not required to go to testing centers for testing for COVID-19 [16]. Instead, related government units called them and recommended a public health representative to visit them at home for the testing. All services for older adults were provided free of charge.

The role of technology in combating the pandemic was apparent in Abu Dhabi. The public messages sent by concerned government agencies stressed the influential roles of technology in keeping communications active, especially concerning older adults [17]. During this social crisis, older adults were encouraged to take advantage of those communication technologies to think about unique opportunities for individual learning, career development, and communicating with family and friends [13]. 
This research focused on older adults (60+ years old) in the Emirate of Abu Dhabi of the United Arab Emirates (UAE) during the COVID-19 pandemic. The COVID-19 countermeasures in Abu Dhabi started to take shape since the pandemic and first reported cases, namely since March of 2020 [17-21]. Due to vast restrictions imposed on the public and, more specifically, on older adults, it was indeed significant to better understand the implications. The study's primary purpose was to investigate specific psychological and social concerns and challenges reported by older adults. The research focused on the most common psychological feelings reported in other international studies. The psychological feelings included fear, loneliness, sadness, irritability, emotional exhaustion, depressive symptoms, sleeping disorders, overeating, and excessive screen use. In addition, the objectives included understanding the effect of new technology and the trend influence of changes imposed, more specifically, the weight of older people. A descriptive approach was adopted, drawing on the Abu Dhabi COVID-19 survey results. This research also aimed to test the effect of time on certain feelings and challenges amongst older adults. It was hoped that the results of this research would provide valuable insights for public social policymakers to understand better the actions they need to take in such crucial circumstances.

The objectives of the study could be expanded into more detailed secondary objectives. They include understanding the descriptive nature of the ten psychological feelings felt most by older adults (mainly using descriptive means and standard deviations of the psychological feelings); understanding the changes in the ten psychological feelings according to time (mainly using trend analysis of the ten psychological feelings as dependent variables, where time was treated as the only independent variable); identifying the most severe challenges that elderlies feel during the pandemic (mainly using descriptive means and standard deviations of the challenges faced by older people); understanding the pandemic effects on the bodyweight of older adults (mainly percentages of older adults scoring on each of the five possibilities concerning weight loss); understanding the effect of staying at home during the pandemic using new technologies (mainly means and standard deviations of each of the practices); and understanding the differences in mean reactions between the sample of older adults (+60 years old) and the rest (all age categories).

\section{Literature Reviews}

Older adults are at a significantly increased risk of severe disease following infection from COVID-19. The WHO announced in April 2020 that more than 95\% of COVID-19 deaths were among people over 60 years of age, and more than half of all deaths occurred in people of 80 years plus [18]. In Sweden, for example, $90 \%$ of the deaths from COVID19 were among people more than 70 years of age [19]. Furthermore, there have been distressing international news and reports of older people abandoned in care homes during the pandemic $[20,21]$. In addition, numerous media coverage and online commentary about the potential rationing of care with older people suggest that older adults are potentially more disadvantaged than persons in other age groups [22,23].

The COVID-19 pandemic literature, in general, has reflected concerns related to common health issues and mental health risks associated with older adults. Apart from some physical health issues such as weight loss [24,25], the literature has recorded a wide range of psychological feelings, challenges, and concerns reported by people during the pandemic. These psychological feelings and challenges include untold fear and suffering [3], sadness [26], loneliness [6,26], stress [27,28], irritability [29] (Patel, 2021), emotional exhaustion [30], depression [26], sleeping disorders [31], overeating [32], and excessive screen use [33]. Research has also concentrated on various concerns and challenges affecting the whole community in general and older adults, including imposed restrictions [6,26], not being able to go out in public [34], disturbance of social life [27], less physical activities [18], less access to regular medical visits [35], less get-togethers with younger children [34], and loneliness $[6,26]$. 
Social isolation has been identified as a severe public health concern among older people [36,37]. As a subjective and complex emotion, loneliness reflects a lack of contact with or physical separation from family and friends. The isolation might be broadened to include social networks and the lack of involvement in social activities. Some [38] have stressed that social isolation is usually experienced as a feeling of anxiety and dissatisfaction associated with a 'lack of connectedness or communality with others, and a deficit between the actual and desired quality and quantity of social engagement.' It is worth noticing that social isolation and loneliness are correlated and often used interchangeably [39]. Most studies have acknowledged that older people's social isolation and loneliness are essential and paramount due to the detrimental and influential impact on their mental and physical health [40]. Loneliness is a real risk factor to the health and well-being of all people, where older people can be more vulnerable to being lonely [26]. Social isolation and loneliness increase older people's risk of anxiety, depression, cognitive dysfunction, heart disease, and mortality [41]. Social isolation might lead to other outcomes, affecting older adults level of awareness and knowledge.

In addressing the challenges faced by older people, some [42] have elaborated that we need to examine both the physical and social impact and the underlying reasons. Empirical research has shown that COVID-19 negatively impacted older adults' body weight and nutritional status [24,25,42], suggesting a higher risk for lockdown-induced weight loss for the older population. The results of the Canadian Perspective Survey indicated a significant impact of COVID-19 on screen time and mental health [43], as more than $60 \%$ of respondents reported increasing TV time and internet usage. Similarly, [44] reported that the COVID-19 pandemic had increased people's screen time for various reasons, including increased time spent on virtual education, working from home, online shopping, and electronic communication with friends and family. The positive association between family members' older adults' wellbeing has been studied in many settings [45]. Some [46] used logistic regression to determine how family size affects psycho-social, economic, and health wellbeing in old age in Mexico. Their study showed that having fewer children is associated with a lower economic wellbeing and higher odds of being uninsured for the older cohort. Older adults with children are more likely than older adults without children to have frequent social interactions. Social contacts such as this offer emotional and instrumental support that enhances wellbeing throughout the life course, and the importance of these contacts is especially evident at advanced age levels [47].

In terms of public policies and programs, health and social care policies and campaigns worldwide acknowledged the issue of loneliness and social isolation well before COVID-19. For example, the Campaign to End Loneliness in the UK helped create a vast network of national, regional, and local organizations to work cohesively and ensure that the social isolation and loneliness of older people remain a public health priority [48]. In addition, the New Zealand government has emphasized its commitment to an aggressive vision of positive aging principles to promote community participation and prevent social isolation and loneliness [49].

It should be realized that in most developed countries, a different population of older people at risk of becoming more socially isolated resides in residential care homes. During the COVID-19 pandemic, such elderlies encountered challenges as their family members and friends were not permitted to visit them, although most countries adopted regular consultation with medical and related professionals to support older people [50]. Therefore, there is an urgent need to support older people as there might be more negative impacts on their physical and mental health from social isolation and ageist discourses around COVID-19. In such conditions, older adults might require more support to have and retain their connectedness and communality to better enable a sense of belonging. In the United Kingdom (UK), an example of support was rendered by Public Health England, which issued a publication of guidance on maintaining mental health and wellbeing during COVID-19 social restrictions [51]. The UK government also embarked on a media campaign to recruit volunteers to support older people who needed assistance. 
The campaign was taken as an inclusive approach to ensure that older people are not left isolated over an extended period. Other responses to socially support older people included the development of social networks through online technologies.

The adverse effects of COVID-19 are more severe and compounded for older adults who do not have access to modern technology platforms or could not acquire more effective means of communication [52]. Empirical research has focused on the technical aspects of the pandemic related to older adults [6,50]. Several studies have promoted online technologies to provide social support networks and a sense of belonging during the pandemic [53]. Some have also suggested that cognitive-behavioral and psychological therapies be delivered online to decrease loneliness and improve mental wellbeing [6]. Other creative ways of supporting the general population, including older people, included more creative online applications and online platforms [54]. However, such technological aiding facilities might be inhibited by disparities among the older population in the access to or literacy in digital resources [50]. As a result, some analysts recommended that interventions involve more frequent communications via telephone, messaging, SMS, or other simple social media resources [55-57].

\section{Methods and Design}

\subsection{The Survey Instruments}

The Abu Dhabi Community Development Department (ADDCD) developed the survey instrument in cooperation with the Statistics Department Abu Dhabi (SCAD). The relevant literature provided the basis for the essential dimensions in the survey to be developed, mainly threats and challenges that elderlies might experience during rough times such as COVID-19. Several international surveys were consulted [58-60].

The original instrument included a multitude of dimensions such as time-related expectations, COVID-19 awareness and attitude, economic and business challenges, educationrelated concerns, health concerns, mental health concerns, community and daily practices, technology-related challenges, and concerns about and trust in government responses. The survey was modified as time went by to include relevant variables according to the pandemic developments. This current study selected the following elements from the survey relevant to the theme of the study. The survey asked respondents to rate on a scale of 5 the extent of some psychological feelings being developed since the outbreak of the COVID-19 pandemic: fear, loneliness, sadness, stress, irritability, emotional exhaustion, depressive symptoms, sleeping disorders, overeating, and excessive screen use. The survey also asked older adults to rate on a scale of 5 the degree of eight specific challenges. They included more restrictions imposed, not being able to go out to public places, social life disturbed more than before, lack of physical activity, lack of access to regular medicine/physiotherapy, not having necessities like food, not seeing grandchildren whenever desired, and being lonely. In addition, the survey asked older adults to portray their level of agreement on a scale of five with the role of technology. Four items were included: 'new technologies contribute to a better quality of life'; 'I can usually figure out new high-tech products and services without help from others'; 'sometimes technology systems are not designed for use by ordinary people'; and 'technology lowers the quality of relationships by reducing personal interactions.' The survey also asked older adults to rate their level of interest in seeing their primary care physician via a virtual visit, from 1 (not at all interested) to 5 (very interested). For those who selected 'very interested' or 'somewhat interested,' a list of reasons was provided to understand better why they were interested in seeing their physicians online. Finally, a question asked respondents about their weight status if the pandemic had any impact. The options included a 5-point Likert scale from underweight to overweight. A further question was asked to identify the number of kilograms gained or lost for overweight or underweight. The survey was administered from February to September 2020. With regard to the demographics of respondents, the survey collected various information concerning age, gender, level of education, residential location and 
region, type of residents, monthly household income, nationality, marital status, number and type of family members, type and category of work, and health characteristics.

\subsection{Study Sample and Survey Distribution}

The study sample included residents across the three regions of Abu Dhabi: Abu Dhabi region, $\mathrm{Al}$ Ain region, and $\mathrm{Al}$ Dhafra region. The survey team made extra efforts to reach all community residents to achieve representative samples. The survey acquired more than 33,000 responses, among which older adults (60+ years old) accounted for 578 respondents. The survey was available in Arabic, English, and six other Asian languages. The survey was distributed online. More than 50 survey links were created and distributed amongst the various segments of the community. Both ADDCD and SCAD were involved in distributing the survey links. ADDCD also sent encouraging calls to the communities, inviting their participation in the survey. The survey was distributed in two stages, at the start of the COVID-19 pandemic and after four months. Means of distribution included phone calls, messengers, emails, and social media. Survey representatives also appeared in several national TV newscasts to encourage participation. It should be added here that the online means of distribution facilitated reaching respondents who were not in the country at the time of distribution.

\subsection{Analysis Methods}

The analysis mainly used descriptive analysis, $t$-tests, analysis of variance (ANOVA), and simple trend analysis. To understand respondents' psychological feelings, concerns during the pandemic, and views on the effect of new technologies, we presented the means, standard deviations, and one-sample $t$-tests for the older adults compared to other age groups. The two-staged survey distribution allowed us to capture the effect of more restrictions imposed on older adults in Abu Dhabi in the post-COVID-19 era. We utilized simple regression for the trend in psychological feelings by recording the $t$-values and their associated significance levels. To understand the pandemic concerns, we utilized simple descriptive statistics of means and standard deviations and the appropriate onesample $t$-tests. In addition, we presented the percentages of the mean changes in weights of respondents. The means of the overall level of agreement with the role of technology was also addressed along with the one-sample $t$-tests. For the psychological feelings, challenges and concerns, and the reactions regarding new technologies, further analysis (one-sample t-tests) explored the mean differences between the older adults' sample and the whole sample of respondents in all age categories. To understand differences according to gender, marital status, and education attainment, we performed analysis of variance (ANOVA). The software (SPSS-27) was used throughout the analysis [61].

\section{Results}

Table 1 shows the breakdown regarding specific categories. About $60 \%$ were male and $40 \%$ were female. Most of them were married $(82.4 \%)$, while only $(7.7 \%)$ were single. Around (3.1\%) were separated, widowed, or divorced. About $40 \%$ were Emirati and $60 \%$ were non-Emiratis. Regarding education attainment, the most significant percentage (39.4\%) of the elderlies held a bachelor's degree, while 3.7\% held doctorate degrees. Those not holding any degrees below bachelor's degrees accounted for (47.5\%). Regarding housing, more than $42.8 \%$ lived in a villa, $46.9 \%$ in an apartment, $2.9 \%$ in collective housing, and $7.4 \%$ in other forms of housing. It should be realized that the percentages of the different categories reflect the accurate representations of each Abu Dhabi. However, regarding nationality, Emiratis in Abu Dhabi are less than the $40 \%$ that is reflected in the response rates. Therefore, specific weighting was used to represent the actual percentages for this category. No differences were observed compared to unweighted results. We should reflect here that both Emiratis and non-Emiratis experienced the same healthcare attention from the public institutions in the country. 
Table 1. Respondent's profile.

\begin{tabular}{|c|c|}
\hline Gender & Percentage \\
\hline Male & $60.1 \%$ \\
\hline Female & $39.9 \%$ \\
\hline \multicolumn{2}{|l|}{ Marital status } \\
\hline Married & $82.4 \%$ \\
\hline Single & $7.7 \%$ \\
\hline Divorced & $1.5 \%$ \\
\hline Separated & $0.8 \%$ \\
\hline Widowed & $0.8 \%$ \\
\hline \multicolumn{2}{|l|}{ Education level } \\
\hline Illiterate & $1.3 \%$ \\
\hline Below secondary school & $4.2 \%$ \\
\hline Secondary school & $15.6 \%$ \\
\hline Post-high school training certificate & $17.7 \%$ \\
\hline College diploma & $8.8 \%$ \\
\hline Bachelor's degree & $39.4 \%$ \\
\hline Master's degree & $8.3 \%$ \\
\hline Doctorate degree & $3.7 \%$ \\
\hline \multicolumn{2}{|l|}{ Age } \\
\hline $60-63$ & $33.0 \%$ \\
\hline $64-67$ & $30.6 \%$ \\
\hline $68-71$ & $21.3 \%$ \\
\hline 72 and older & $15.1 \%$ \\
\hline \multicolumn{2}{|l|}{ Nationality } \\
\hline Emirati & $40.3 \%$ \\
\hline Non-Emirati & $59.7 \%$ \\
\hline \multicolumn{2}{|l|}{ Housing type } \\
\hline Villa & $42.8 \%$ \\
\hline Apartment & $46.9 \%$ \\
\hline Collective housing & $2.9 \%$ \\
\hline Other types & $7.4 \%$ \\
\hline \multicolumn{2}{|l|}{ Live alone or with others? } \\
\hline I live alone & $9.36 \%$ \\
\hline Share home with others & $90.64 \%$ \\
\hline
\end{tabular}

Most of the older adults were recorded between 60 and 67 years old (64.6\%). Respondents also noted that $(9.36 \%)$ of them lived alone, while $90.64 \%$ had at least one person living with them.

Psychological feelings-The results in Table 2 show the means and standard deviations regarding self-reported psychological feelings during the pandemic. The mean values for these psychological health attributes were relatively low (below 3.0), with the highest mean of 3.2314 for excessive screen use, 2.6552 for fear, 2.6534 for loneliness, and 2.6063 for stress. On the other hand, the feelings of depressive symptoms and overeating scored among the lowest, at 1.9203 and 1.9059, respectively. Further ANOVA revealed no differences regarding gender and marital status. 
Table 2. Psychological feelings during the pandemic.

\begin{tabular}{cccccc}
\hline Psychological Feelings & Mean & Rank & Standard Deviation & $\boldsymbol{t}$-Value & Sig. \\
\hline Fear & 2.6552 & 2 & 1.165 & -4.068 & 0.001 \\
Loneliness & 2.6534 & 3 & 1.301 & -0.985 & 0.325 \\
Sadness & 2.4960 & 5 & 1.230 & -4.695 & 0.001 \\
Stress & 2.6063 & 4 & 1.252 & -7.400 & 0.001 \\
Irritability & 2.2941 & 7 & 1.201 & -8.434 & 0.001 \\
Emotional exhaustion & 2.3571 & 6 & 1.261 & -7.188 & 0.001 \\
Depressive symptoms & 1.9203 & 9 & 1.203 & -7.754 & 0.001 \\
Sleeping disorder & 2.0745 & 8 & 1.293 & -7.663 & 0.001 \\
Overeating & 1.9059 & 10 & 1.150 & -10.297 & 0.001 \\
Excessive screen use & 3.2314 & 1 & 1.355 & -6.777 & 0.001 \\
\hline
\end{tabular}

However, significant differences were observed for educational attainment regarding five of the psychological feelings (loneliness, irritability, emotional exhaustion, sadness, and overeating), where those below college degrees recorded the highest means. A one-sample $t$-test (comparing the means to the overall population mean of all ages) resulted in the significance of all psychological feelings except (loneliness). The negative $t$-values indicate that older adults provided (smaller) means for the corresponding feelings compared to the rest of the population sample in the survey.

Trends in psychological feelings-The analysis took each of the ten psychological feelings as dependent variables, where time was treated as the only independent variable. Table 3 shows the parameters that resulted in ten individual regression analyses. Only two variables, sleeping disorders and overeating, showed significance at the 0.05 level. The positive standardized coefficients and $t$-values note more negative development for the two feelings for older adults, suggesting that time harms the development of the two feelings. The same analysis for those below 60 years shows significant differences concerning four variables—stress, irritability, emotional exhaustion, and excessive screen use.

Table 3. Regression analyses of perception of the ten psychological feelings.

\begin{tabular}{|c|c|c|c|c|c|}
\hline \multirow[t]{2}{*}{ Model } & \multicolumn{2}{|c|}{$\begin{array}{l}\text { Unstandardized } \\
\text { Coefficients }\end{array}$} & \multirow{2}{*}{$\begin{array}{c}\begin{array}{c}\text { Standardized } \\
\text { Coefficients }\end{array} \\
\text { Beta }\end{array}$} & \multirow[t]{2}{*}{$t$-Value } & \multirow[t]{2}{*}{ Sig. } \\
\hline & B & Std. Error & & & \\
\hline Fear & 0.012 & 0.011 & 0.055 & 1.057 & 0.291 \\
\hline Loneliness & 0.004 & 0.013 & 0.018 & 0.335 & 0.738 \\
\hline Sadness & -0.010 & 0.012 & -0.045 & -0.845 & 0.398 \\
\hline Stress & 0.014 & 0.012 & 0.060 & 1.137 & 0.256 \\
\hline Irritability & 0.013 & 0.012 & 0.060 & 1.132 & 0.258 \\
\hline $\begin{array}{l}\text { Emotional } \\
\text { exhaustion }\end{array}$ & 0.014 & 0.012 & 0.059 & 1.121 & 0.263 \\
\hline $\begin{array}{l}\text { Depressive } \\
\text { symptoms }\end{array}$ & 0.006 & 0.012 & 0.028 & 0.524 & 0.601 \\
\hline Sleeping disorder & 0.027 & 0.012 & 0.114 & 2.181 & 0.030 \\
\hline Overeating & 0.025 & 0.012 & 0.114 & 2.177 & 0.030 \\
\hline Excessive screen use & 0.019 & 0.013 & 0.075 & 1.412 & 0.159 \\
\hline
\end{tabular}

Pandemic concerns-Table 4 shows the most severe challenges that elderlies feel during the pandemic. Again, three variables scored a value above 3.0. Regarding the most severe challenges that elderlies are experiencing during the pandemic, the variable 'more restrictions imposed' on elderlies stood alone with the highest level of concern (3.462), followed by 'unable to see children and grandchildren whenever desired or wanted' (3.124) and 'not being allowed in public places' (3.056). 
Table 4. Older adults' major concerns and challenges.

\begin{tabular}{cccccc}
\hline Challenges & Means & Ranks & Standard Deviations & $t$-Value & Sig. \\
\hline $\begin{array}{c}\text { Being lonely } \\
\begin{array}{c}\text { Not being able to see my } \\
\text { grandchildren whenever }\end{array}\end{array}$ & 2.427 & 7 & 1.207 & -17.301 & 0.001 \\
$\begin{array}{c}\text { I want } \\
\text { Not having necessities } \\
\text { like food }\end{array}$ & 2.555 & 6 & 1.323 & 0.78 & 0.938 \\
$\begin{array}{c}\text { Lack of access to regular } \\
\text { medicine/physiotherapy }\end{array}$ & 2.315 & 8 & 1.403 & -6.602 & 0.001 \\
$\begin{array}{c}\text { Lack of physical activity } \\
\text { Social life disturbed } \\
\text { more than before }\end{array}$ & 2.654 & 5 & 1.303 & -4.579 & 0.001 \\
$\begin{array}{c}\text { Not being able to see my } \\
\text { grandchildren whenever } \\
\quad \text { I want }\end{array}$ & 3.124 & 2 & 1.261 & 4.332 & 0.001 \\
$\begin{array}{c}\text { More restrictions } \\
\text { imposed }\end{array}$ & 3.462 & 1 & 1.194 & -0.768 & 0.443 \\
\hline
\end{tabular}

On the contrary, the three variables that received the lowest concern were 'lack of access to regular medicine/physiotherapy', 'being lonely', and 'not having necessities like food'. About $29.24 \%$ of older adults indicated that they are interested in seeing their primary care physician via video during and after COVID-19. This question also asked respondents to elaborate further on the reasons for seeing their physician. The four main reasons elderlies are interested in seeing their physician via virtual visit after COVID-19 were prescription renewals, addressing a common illness (i.e., cold, flu), managing chronic illness, and psychological consultation.

A one-sample $t$-test resulted in the significance of five of the challenges. They included (being lonely, not having necessities like food, lack of access to medicine, lack of physical activity, and more restrictions imposed). The nonsignificant concerns indicate more similarity between the older adults' challenges and those of other sample categories. Further ANOVA of the pandemic concerns revealed no gender and marital status differences. However, significant differences were observed for educational attainment regarding the significant concerns or challenges (loneliness, emotional exhaustion, and sadness). Again, those below college degrees recorded the highest means.

Other pandemic effects and reactions-The results, in general, do not indicate that the pandemic had a significant effect on the body weight of older adults. Only $2.47 \%$ felt that they gained too much weight. About $20.85 \%$ felt that they gained weight. The majority $(65.37 \%)$ felt that they maintained their weight. Meanwhile, $9.47 \%$ perceived losing weight, and $1.77 \%$ said they lost too much. For older adults and those who reported a gain in weight, the mean of gained weight was $4.32 \mathrm{~kg}$. For those who reported weight loss, the mean of lost weight was $5.52 \mathrm{~kg}$ (Table 5). Further ANOVA of other pandemic effects and reactions on weights revealed no gender, marital status, or educational attainment.

Table 5. Overall weight (changes).

\begin{tabular}{cc}
\hline Weight Changes & Percentage \\
\hline Lost too much weight & $1.77 \%$ \\
Lost some weight & $9.47 \%$ \\
Maintained my weight & $65.37 \%$ \\
Gained weight & $20.85 \%$ \\
Gained much weight & $2.47 \%$ \\
\hline
\end{tabular}

Communication and technology-For staying at home during the pandemic, it was necessary to explore further the perception and readiness of elderlies to deal with new technology. The mean scores for the four statements concerning the role of technology 
are shown in Table 6. The highest mean was assigned to 'new technology contributes to a better quality of life,' as older adults recorded a mean of 3.866. The statement 'I can figure out new high-tech products and services without help from others' recorded a mean of 3.543. The statement 'sometimes new technologies are not designed for use by ordinary people' scored a mean of 3.665. Finally, 'technology lowers the quality of relationships by reducing personal interactions' scored a mean of 3.795. In general, all four means were above the middle point of 3.0 .

Table 6. Overall level of agreement with the role of technology.

\begin{tabular}{cccc}
\hline Technology & Mean & $t$-Value & Sig. \\
\hline $\begin{array}{c}\text { New technologies contribute to a } \\
\text { better quality of life }\end{array}$ & 3.866 & -2.529 & 0.043 \\
$\begin{array}{c}\text { I can usually figure out new } \\
\text { high-tech products and services } \\
\text { without help from others } \\
\begin{array}{c}\text { Sometimes technology systems } \\
\text { are not designed for use by } \\
\quad \text { ordinary people }\end{array}\end{array}$ & 3.543 & -5.996 & 0.001 \\
$\begin{array}{c}\text { Technology lowers the quality of } \\
\text { relationships by reducing } \\
\text { personal interactions }\end{array}$ & 3.665 & 0.311 & 0.756 \\
\hline
\end{tabular}

One-sample $t$-test results of the significance of the four new technology-related variables produced significance regarding two of the variables (new technologies contribute to a better quality of life and figure out new high-tech products without help from others). For both variables, older adults reported smaller mean values. The further ANOVA of the pandemic concerns revealed no gender and marital status differences. For educational attainment, significant differences were observed regarding the psychological feelings of (loneliness, emotional exhaustion, and sadness). Those below college degrees recorded the highest means.

\section{Discussion}

The study investigated significant developments concerning older adults during the pandemic. It explored their perception regarding ten psychological feelings. Moreover, it examined if the feelings changed during the pandemic. The analysis also investigated older adults' concerns and challenges faced during the pandemic. In addition, the investigation looked closer at their perception of health and related issues concerning losing or gaining weight and opportunities for seeing their medical advisors. Finally, it presented older adults' opinions about the role and effect of technology while staying at home. In many survey questions, older adults provided mean responses, which were lower than the total respondents who participated in the survey. Depending on the nature of the question, most older adults provided means lower in magnitude than those of other age brackets in the population sample.

Relevant research in other countries supports the presence of certain psychological feelings with older adults in Abu Dhabi. The result of excessive screen time during the pandemic for older adults in Abu Dhabi is consistent with the results reported in several studies $[33,44]$. Among these findings, the issue of loneliness as a significant feeling for older adults has taken center-stage attention in older adults' related research around the world, for which the present Abu Dhabi study provides further support. Our results consistently suggest that loneliness is a real risk factor to the health and well-being of all people, especially older people who could be more vulnerable to being lonely [51,62]. In addition, the reported feeling of stress is evident in the Abu Dhabi study, which is in line with the empirical findings $[27,28]$. Overall, the results from Abu Dhabi echo other international research that shows that the COVID-19 pandemic has been a significant stressor that has affected older adults worldwide [30]. 
However, we should also note that the perceived level of various psychological feelings or disorders associated with the COVID-19 pandemic tends to be low among Abu Dhabi's older adults. Some psychological feelings such as irritability, emotional exhaustion, depressive symptoms, sleeping disorders, and overeating received relatively low means. Such results are not consistent with similar surveys of elderlies in other communities worldwide [29,30]. It is worth emphasizing that, on the one hand, Abu Dhabi and the UAE, in general, have government institutions and specific policies dealing with the wellbeing of older adults. For example, the government of Abu Dhabi issued many policies that centered on older adults and the issue of social connection [63]. On the other hand, the traditionally extensive and strong social connection has remained in the modern life of Abu Dhabi, where older adults usually live at home with other family members. Inside the family, they are allowed to practice minimum isolation procedures during the pandemic (i.e., reduced visits from family members and social distancing among family members). In this case, the circumstances in other countries may be relatively different from Abu Dhabi $[6,26,64]$. When we focus on the psychological feelings, pandemic concerns, effects on weights, and effect of technology, the results indicate no significant differences in gender and marital status in all related variables. However, some more negative outcome variables were significantly different for those holding below-college degrees.

In this context, the UAE is known for nursing care at home or Home Health Care (HHC) rather than nursing homes. Home care has multiple benefits, from companionship to promoting aging with dignity [65]. Home care has also carefully selected nurses and professionals who are passionate and well-trained. Indeed, HHC foraging has become the preferred solution for the older adult population. When provided the opportunity, most senior citizens prefer to live out their later years in the comfort and familiarity of their homes. With the help of licensed medical professionals, they can avoid moving to an unfamiliar assisted living facility. There are relatively few older adult care facilities in the $\mathrm{UAE}$, where the norm remains that caring for older adults is the duty of family members.

For Abu Dhabi's older adults, the ten perceived psychological feelings experienced relatively minor changes during and post-COVID-19. The few months had some adverse effects only on sleeping disorders and overeating. It seems that spending more time at home produced some restrictions and plenty of spare time. Research in other countries also produced such effects [31]. However, it should be noted that most research concerning sleeping or overeating covered the general population $[3,66]$.

Regarding COVID-19-related challenges, it was clear that older adults saw more restrictions imposed on them to be more of a challenge than other age categories. This specific result entails the feelings of isolation noted by [67]. Social isolation might be due to environmental and policy restrictions rather than an individual's ability to create or maintain social relationships [6,26]. The COVID-19-related restrictions imposed by the Abu Dhabi government also included fewer or restricted visits of family members, which explains the second-highest rated challenge by older adults, that is, 'unable to see children and grandchildren whenever desired or wanted.' Such a concern was referred to in many papers [67]. Furthermore, elderlies in Abu Dhabi also ranked 'not being allowed to public places' as a significant concern. Similar results have also been reported in other countries such as Japan [34]. However, those three low-rated challenges or concerns, i.e., lack of access to regular medicine/physiotherapy, loneliness, and lack of necessities such as food and medicine, are not consistent with the research findings in other countries [35].

The results of this study pointed out that older adults in Abu Dhabi felt comfortable figuring out new high-tech products and services without help from others. They also tended to have a more favorable attitude toward virtual technology and appreciate the role of new technology in contributing to a better quality of life, which is consistent with research findings in other countries [21]. However, Abu Dhabi's older adults realized that, sometimes, new technologies are not designed for use by people with low technology literacy. Moreover, they pointed to the adverse effects of technology in lowering the quality of relationships by reducing personal interactions. Such results support the efforts of public 
institutions in Abu Dhabi and elsewhere [20]. In Abu Dhabi, public messages sent to communities by government authorities encouraged all family members, especially older adults, to upload mobile applications that facilitate visual communications online. They also offered tutorials for educating older adults.

This research explored people's understanding of the effect of the COVID-19 pandemic on their preference to shift in health care delivery platforms, necessitating a new reliance on technology and telemedicine. The results indicated that a relatively low percentage of older adults in Abu Dhabi reported a positive response of their interest to see their primary care physician via a virtual visit during and after the COVID-19 pandemic, much lower than some reported figures of older adults that completed or scheduled telemedicine visits in other parts of the world [68-74]. This outcome may be explained by the privileges that the government of Abu Dhabi has given to older adults during the pandemic, as government medical facilities were encouraged to call elderlies to request home visits [12], and all services to elderlies were provided free of charge.

The research included specific symptoms such as fear, loneliness, sadness, stress, irritability, emotional exhaustion, depressive symptoms, sleeping disorders, and overeating. However, one limitation in this study has to do with the fact that each symptom was asked by one question. Hence, one might doubt if respondents could accurately reflect the situation. Another limitation is that the socio-demographic characteristics of participants were not covered fully regarding the psychological feelings. We should also refer to some potential limitations derived from the sample collection that could be avoided in the future. First, the survey depended mainly on online distribution. Future similar surveys could solicit older adults' responses by conducting home visitations and interviews for those with reservations regarding online technology. Several months after this specific survey, vaccination started in the UAE. Future research might address how the availability of vaccination might have changed the results.

\section{Conclusions}

This research acknowledges that many papers have already discussed older adults mental health issues during the COVID-19 lockdown. However, we should stress that the Abu Dhabi community has unique features. Older adults in Abu Dhabi live within a unique culture where they have special uniqueness regarding tradition, respect, and social connection. This paper adds many new pieces of knowledge in this area.

Regarding the first objective, the overall self-reported psychological feelings during the pandemic recorded relatively low values (below 3.0 out of 5). Excessive screen use recorded the highest mean. The psychological feelings of fear, loneliness, and stress recorded the highest means. On the other hand, feelings such as depressive symptoms and overeating scored lowest. For the second objective, the trend analysis of ten psychological feelings with time recorded significant negative changes for only two of the psychological feelings, sleeping disorders and overeating. The third objective dealt with specific challenges encountered by older adults. The highest challenges were more restrictions imposed on elderlies, unable to see children and grandchildren whenever desired or wanted, and not being allowed in public places. The challenges with the lowest concerns were the lack of access to regular medicine/physiotherapy, loneliness, and lack of necessities like food. The fourth objective dealt with the effect of the pandemic on the body weight of older adults. The results showed that only a quarter of older adults' recorded gaining weight, as most maintained their weight. The final objective was to explore further the perception and readiness of elderlies to deal with new technology. The older adults assigned a high importance score, describing new technology to contribute to a better quality of life. However, they recorded a severe concern regarding their need to receive more help and assistance regarding new high-tech products and services. They saw it as 'not designed for use by ordinary people', and the worry that 'technology lowers the quality of relationships by reducing personal interactions'. 
The Abu Dhabi study provides further support that loneliness is a real risk factor to the health and wellbeing of older people who are more vulnerable to being lonely. Overall, the results echo other international research that shows that the COVID-19 pandemic has been a significant stressor that has affected older adults. Contrary to results in other countries, some psychological feelings such as irritability, emotional exhaustion, depressive symptoms, sleeping disorders, and overeating did not show severe concerns in Abu Dhabi. In this regard, it is worth emphasizing that government policies dealing with the wellbeing of older adults provided some positive reactions. The traditionally extensive and strong social connection has remained a primary supporting feature for families living in Abu Dhabi as cultural aspects of closeness have enriched the opportunity for older adults to still be close to their loved ones at home. Overall, the results showed no significant differences in gender and marital status in all related variables. Overall, the feelings of isolation for older adults were enhanced by the more restrictions imposed on them. As a result, their inability to see their children and grandchildren was a significant challenge. The results revealed that older adults witnessed a more favorable attitude toward virtual technology as they appreciate its roles in contributing to a better quality of life. However, they realized that sometimes new technologies are not designed for use, as they might not be prepared enough to deal with it, as it lowers the quality of relationships by reducing personal interactions. However, they were encouraged by related government authorities' support with mobile applications that facilitate visual communications online. They also offered tutorials for educating older adults.

In a relative sense, older adults in Abu Dhabi rated some specific psychological health attributes as more challenging, including excessive screen use, fear, loneliness, and stress. They rated the feelings of depressive symptoms and overeating relatively low. Trend analysis showed significant changes in sleeping disorders and overeating and pointed to improvements in other feelings but not significantly. Older adults revealed several concerns associated with the pandemic, such as more restrictions imposed on elderlies, not seeing children and grandchildren whenever desired or wanted, and not being allowed to go to public places. On the other hand, they did not show much concern concerning the lack of access to regular medicine/physiotherapy and not having necessities.

During difficult times such as the COVID-19 pandemic, a powerful family bond can make all the difference in the world for older adults. Families provide a stable foundation for emotional support for their loved ones. The home environment is the least restrictive place for older adults to remain engaged with their typical daily activities in the community and with family and friends around them. Abu Dhabi government institutions could further design volunteer schemes to better communicate with older adults. For example, special volunteers could have home visits to educate older people to use IT and virtual applications. Such initiatives might increase their health awareness levels and enrich their pandemic knowledge. In addition, such home visit projects by volunteers or medical teams could act as ambassadors to educate older adults and senior citizens about coronavirus-related preventive measures.

Future research should investigate if different people had a different definition of these symptoms. There is a need to understand better the existence of significant differences in gender, age, education status, income status, marital status, nationality, and other relevant characteristics. More analysis is needed to provide elaborations on the meanings or definitions of each term to guarantee they meant the same thing. Knowing baseline characteristics of the elderly respondent, their comorbidities, and pre-pandemic psychological conditions could help further understand the specific impact of the pandemic on mental health. Future research should also investigate the effect of the number of people and older adults' quality of life in more comprehensive ways. It should also be said that multiple regression analysis is only shown for psychological feelings. More analysis could investigate the association between physiological concerns and other variables (i.e., demographic). Such results could provide more relevant information to enrich policymaking accordingly. A further objective should try to revisit the issues raised by this study to 
confirm the results and continue exploring the effects of family settings. When it comes to times of more complex circumstances such as pandemics, being consistent with other international research, it might be more informed to include other related variables such as smoking, sport and activities, specific social behaviors, and economic-related variables in order to generate a more comprehensive picture of older adults' wellbeing. In addition, a comparison between Abu Dhabi and another aging-developing country may be helpful for better policy makings.

Author Contributions: M.A.B.: conceptualization, methodology, software, validation, formal analysis, investigation, and original draft preparation. M.A.A.: validation, investigation, review and editing, and supervision. H.A.: validation, supervision, and project administration. G.Y.: methodology, validation, project administration, and review and editing. M.A.: methodology, validation, and review and editing. B.A.: methodology, validation, and review and editing. L.A.: methodology, validation, and review and editing. A.A.: software, data curation, review and editing, visualization, and project administration. All authors have read and agreed to the published version of the manuscript.

Funding: This research received no external funding.

Institutional Review Board Statement: The study was conducted according to the guidelines of the Declaration of Helsinki, and approved by the Institutional Review Board of DCD and SCAD.

Informed Consent Statement: Informed consent was obtained from all subjects involved in the study.

Data Availability Statement: The data presented in this study are available on request from the corresponding author. The data are not publicly available, due to privacy restrictions.

Acknowledgments: The Abu Dhabi Department of Community Development and the Statistics Center Abu Dhabi approved this study. The data were part of the Second Cycle of Abu Dhabi Quality of Life Survey.

Conflicts of Interest: The authors declare that there has been no conflict of interest.

\section{References}

1. World Health Organization (WHO). Older People \& COVID-19. 2021. Available online: https://www.who.int/teams/socialdeterminants-of-health/demographic-change-and-healthy-ageing/covid-19 (accessed on 16 October 2021).

2. OCHA Services. Bearing the Brunt: The impact of COVID-19 on Older People in Low-And Middle-Income Countries-Insights from 2020. 2021. Available online: https:/ / reliefweb.int/report/world/bearing-brunt-impact-covid-19-older-people-low-andmiddle-income-countries-insights (accessed on 2 August 2021).

3. United Nations. Policy Briefs: The Impact of COVID-19 on Older Persons. 2020. Available online: https://unsdg.un.org/sites/ default / files/2020-05/Policy-Brief-The-Impact-of-COVID-19-on-Older-Persons.pdf (accessed on 13 September 2021).

4. Oxford COVID-19 Evidence Service. Global COVID-19 Case Fatality Rates. 2020. Available online: https://www.phc.ox.ac.uk/ covid-19/evidence-service/reviews/global-covid-19-case-fatality-rates (accessed on 20 June 2021).

5. Public Health England. Guidance for the Public on the Mental Health and Wellbeing Aspects of Coronavirus (COVID-19). 2020. Available online: https:/ / www.gov.uk/government/publications/covid-19-guidance-for-the-public-on-mental-health-andwellbeing/guidance-for-the-public-on-the-mental-health-and-wellbeing-aspects-of-coronavirus-covid-19\#older-people (accessed on 20 June 2021).

6. Käll, A.; Jägholm, S.; Hesse, H.; Andersson, F.; Mathaldi, A.; Norkvist, B.T.; Shafran, R.; Andersson, G. Internet-based cognitive behavior therapy for loneliness: A pilot randomized controlled trial. Behav. Ther. 2020, 51, 54-68. [CrossRef] [PubMed]

7. Federal Competitiveness and Statistics Authority. The UAE Government's Initiatives to Combat the COVID-19 Crisis. 2020. Available online: https://fcsa.gov.ae/en-us/Documents/The\%20UAE\%20Government\%20Initiatives $\% 20$ to $\% 20$ combat $\% 20$ Covid\%2019.pdf (accessed on 20 June 2021).

8. Ministry of Health and Prevention. Your Health Our Priority-MOHAP Virtual Doctor. 2021. Available online: https://www. mohap.gov.ae/en/AwarenessCenter/Pages/COVID19-Information-Center.aspx (accessed on 20 June 2021).

9. UAE Government Portal. Handling the COVID-19 Outbreak. 2020. Available online: https://u.ae/en/information-and-services/ justice-safety-and-the-law / handling-the-covid-19-outbreak (accessed on 20 June 2021).

10. The Middle East Explained. Latest COVID-19 Rules in Dubai and Abu Dhabi: What You Need to Know. 2021. Available online: https: / www.thenationalnews.com/uae/latest-covid-19-rules-in-dubai-and-abu-dhabi-what-you-need-to-know-1.11 55777 (accessed on 20 June 2021).

11. Emirates Policy Center. UAE Model in Confronting Coronavirus Pandemic. 2020. Available online: https://epc.ae/brief/uaemodel-in-confronting-coronavirus-pandemic (accessed on 13 September 2021). 
12. UAE Health. COVID-19: Abu Dhabi Health Authority Provides Guidelines to Keep the Elderly Safe. 2021. Available online: https:/ / gulfnews.com/uae/health/covid-19-abu-dhabi-health-authority-provides-guidelines-to-keep-the-elderly-safe1.73777296 (accessed on 13 September 2021).

13. Ministry of Health and Prevention. Mobile Healthcare Initiative Enaya. 2020. Available online: https://www.mohap.gov.ae/en/ Aboutus/Pages/ProjectandInitiatives.aspx (accessed on 13 September 2021).

14. Family Development Foundation (FDF). Towards a Healthy and Safe Society' Initiative. 2020. Available online: https://www. wam.ae/en/details/1395302848260 (accessed on 13 September 2021).

15. Authority for Social Contribution (MAAN). Creating Collaborative Communities. 2021. Available online: https://maan.gov.ae/ (accessed on 13 September 2021).

16. SEHA. SEHA's Journey Fighting COVID-19. 2020. Available online: https://www.seha.ae/covid-19-landing/ (accessed on 13 September 2021).

17. The Middle East Explained. Coronavirus: 5 Technologies Inspired by the Pandemic. 2021. Available online: https:// www.thenationalnews.com/uae/science/coronavirus-5-technologies-inspired-by-the-pandemic-1.1036287 (accessed on 13 September 2021).

18. World Health Organization (WHO). Coronavirus Disease (COVID-19). 2020. Available online: https://www.who.int/ emergencies / diseases / novel-coronavirus-2019?gclid=Cj0KCQjwxJqHBhC4ARIsAChq4atab0sWcPnkKI4cM5sSBg8BU55B0 ipBua8BHCpjvr0Jc6GWsrsOkp4aAlqJEALw_wcB (accessed on 16 October 2021).

19. Medical News Today. 2020. Available online: https://www.medicalnewstoday.com/articles/the-impact-of-the-covid-19 -pandemic-on-older-adults (accessed on 16 October 2021).

20. Keeley, G. Corpses of the Elderly Found Abandoned in Spanish Care Homes. 2020. Available online: https://www.aljazeera com/news/2020/03/corpses-elderly-abandoned-spanish-care-homes-200324141255435.html (accessed on 16 October 2021).

21. Sparks, H. Morbid 'Boomer Remover' Coronavirus Meme Only Makes Millennials Seem More Awful. New York Post. 2020. Available online: https:/ /nypost.com/2020/03/19/morbid-boomer-remover-coronavirus-meme-only-makes-millennials-seemmore-awful/ (accessed on 16 October 2021).

22. Haffower, H. A Certain Horrible Subset of the Internet is Calling the Coronavirus 'Boomer Remover'. Business Insider Australia. 2020. Available online: https:/ / www.businessinsider.com/millennials-gen-z-calling-coronavirus-boomer-remover-reddit-20 20-3? $\mathrm{r}=\mathrm{US} \& \mathrm{IR}=\mathrm{T}$ (accessed on 16 October 2021).

23. Lee, K.; Jeong, G.-C.; Yim, J. Consideration of the Psychological and Mental Health of the Elderly during COVID-19: A Theoretical Review. Int. J. Environ. Res. Public Health 2020, 17, 8098. [CrossRef] [PubMed]

24. Owen, A.; Tran, T.; Hammarberg, K.; Kirkman, M.; Fisher, J. Poor appetite and overeating reported by adults in Australia during the coronavirus-19 disease pandemic: A population-based study. Public Health Nutr. 2020, 24, 275-281. [CrossRef] [PubMed]

25. Constandt, B.; Thibaut, E.; De Bosscher, V.; Scheerder, J.; Ricour, M.; Willem, A. Exercising in Times of Lockdown: An Analysis of the Impact of COVID-19 on Levels and Patterns of Exercise among Adults in Belgium. Int. J. Environ. Res. Public Health 2020, 17, 4144. [CrossRef]

26. Santini, Z.I.; Jose, P.E.; Cornwell, E.Y.; Koyanagi, A.; Nielsen, L.; Hinrichsen, C.; Meilstrup, C.; Madsen, K.R.; Koushede, V. Social disconnectedness, perceived isolation, and symptoms of depression and anxiety among older Americans (NSHAP): A longitudinal mediation analysis. Lancet Public Health 2020, 5, e62-e70. [CrossRef]

27. Klaiber, P.; Wen, J.H.; DeLongis, A.; Sin, N.L. The Ups and Downs of Daily Life During COVID-19: Age Differences in Affect, Stress, and Positive Events. J. Gerontol. Ser. B Psychol. Sci. Soc. Sci. 2020, 76, e30-e37. [CrossRef]

28. Van Tilburg, T.G.; Steinmetz, S.; Stolte, E.; Van Der Roest, H.; De Vries, D.H. Loneliness and Mental Health During the COVID-19 Pandemic: A Study Among Dutch Older Adults. J. Gerontol. Ser. B Psychol. Sci. 2020, 76, e249-e255. [CrossRef]

29. Patel, V. Global Mental Health in the Time of COVID-19. Harvard Health Blog. 2021. Available online: https://www.health. harvard.edu/blog/global-mental-health-in-the-time-of-covid-19-2020061620194 (accessed on 16 October 2021).

30. Jeste, D.V.; Di Somma, S.; Lee, E.E.; Nguyen, T.T.; Scalcione, M.; Biaggi, A.; Daly, R.; Liu, J.; Tu, X.; Ziedonis, D.; et al. Study of loneliness and wisdom in 482 middle-aged and oldest-old adults: A comparison between people in Cilento, Italy and San Diego, USA. Aging Ment. Health 2020, 25, 2149-2159. [CrossRef]

31. Pires, G.N.; Ishikura, I.A.; Xavier, S.D.; Petrella, C.; Piovezan, R.D.; Xerfan, E.M.S.; Andersen, M.L.; Tufik, S. Sleep in Older Adults and Its Possible Relations With COVID-19. Front. Aging Neurosci. 2021, 13, 647875. [CrossRef]

32. Altena, E.; Baglioni, C.; Espie, C.A.; Ellis, J.; Gavriloff, D.; Holzinger, B.; Schlarb, A.; Frase, L.; Jernelöv, S.; Riemann, D. Dealing with sleep problems during home confinement due to the COVID-19 outbreak: Practical recommendations from a task force of the European CBT-I Academy. J. Sleep Res. 2020, 29, e13052. [CrossRef]

33. Colley, R.C.; Bushnik, T.; Langlois, K. Exercise and screen time during the COVID-19 pandemic. Health Rep. 2020, 31 , 3-11.

34. Takashima, R.; Onishi, R.; Saeki, K.; Hirano, M. Perception of COVID-19 Restrictions on Daily Life among Japanese Older Adults: A Qualitative Focus Group Study. Healthcare 2020, 8, 450. [CrossRef]

35. Mishra, S.; Bhoi, S.; Ravan, R.; Nath, S.; Kar, N.; Padhy, S. COVID-19 pandemic and care of elderly: Measures and challenges. J. Geriatr. Care Res. 2020, 7, 143-146.

36. Gerst-Emerson, K.; Jayawardhana, J. Loneliness as a Public Health Issue: The Impact of Loneliness on Health Care Utilization Among Older Adults. Am. J. Public Health 2015, 105, 1013-1019. [CrossRef] 
37. Heidinger, T.; Richter, L. The Effect of COVID-19 on Loneliness in the Elderly. An Empirical Comparison of Pre-and Peri-Pandemic Loneliness in Community-Dwelling Elderly. Front. Psychol. 2020, 11, 585308. [CrossRef]

38. Victor, C.R.; Scambler, S.J.; Bowling, A.N.N.; Bond, J. The prevalence of, and risk factors for, loneliness in later life: A survey of older people in Great Britain. Ageing Soc. 2005, 25, 357-375. [CrossRef]

39. Steptoe, A.; Shankar, A.; Demakakos, P.; Wardle, J. Social isolation, loneliness, and all-cause mortality in older men and women. Proc. Natl. Acad. Sci. USA 2013, 110, 5797-5801. [CrossRef]

40. Barth, J.; Schneider, S.; von Känel, R. Lack of Social Support in the Etiology and the Prognosis of Coronary Heart Disease: A Systematic Review and Meta-Analysis. Psychosom. Med. 2010, 72, 229-238. [CrossRef]

41. Holt-Lunstad, J.; Smith, T.B.; Layton, J.B. Social Relationships and Mortality Risk: A Meta-analytic Review. PLoS Med. 2010, 7, e1000316. [CrossRef]

42. Sigh, R. COVID-19 and Challenges of Elderly People. Diplomatist. 2020. Available online: http://diplomatist.com/2020/04/23 /covid-19-and-challenges-of-elderly-people/ (accessed on 16 October 2021).

43. Li, T.; Zhang, Y.; Gong, C.; Wang, J.; Liu, B.; Shi, L.; Duan, J. Prevalence of malnutrition and analysis of related factors in elderly patients with COVID-19 in Wuhan, China. Eur. J. Clin. Nutr. 2020, 74, 871-875. [CrossRef]

44. Helander, M.; Cushman, S.; Monnat, S. A Public Health Side Effect of the Coronavirus Pandemic: Screen Time-Related Eye Strain and Eye Fatigue. Population Health Research Brief Series, Syracuse University. 2021. Available online: https://lernercenter.syr.edu/ 2020/05/26/ib-24/ (accessed on 16 October 2021).

45. Margolis, R.; Myrskylä, M. A Global Perspective on Happiness and Fertility. Popul. Dev. Rev. 2011, 37, 29-56. [CrossRef]

46. Díaz-Venegas, C.; Sáenz, J.L.; Wong, R. Family size and old-age wellbeing: Effects of the fertility transition in Mexico. Ageing Soc. 2015, 37, 495-516. [CrossRef]

47. Baranowska-Rataj, A.; Abramowska-Kmon, A. Number of children and social contacts among older people: The moderating role of filial norms and social policies. Eur. J. Ageing 2018, 16, 95-107. [CrossRef]

48. Ferguson, L. The campaign to end loneliness. Work. Older People 2011, 15, 66-70. [CrossRef]

49. Ministry of Social Development. New Zealand Positive Ageing Strategy; Ministry of Social Development: Wellington, New Zealand, 2001.

50. Berg-Weger, M.; Morley, J.E. Loneliness in Old Age: An Unaddressed Health Problem. J. Nutr. Health Aging 2020, 24, 243-245. [CrossRef]

51. Armitage, R.; Nellums, L.B. COVID-19 and the consequences of isolating the elderly. Lancet Public Health 2020, 5, e256. [CrossRef]

52. Johns Hopkins University. The Impact of COVID-19 on Older Adults. 2020. Available online: https://hub.jhu.edu/2020/05/05 /impact-of-covid-19-on-the-elderly/ (accessed on 16 October 2021).

53. Newman, M.G.; Zainal, N.H. The value of maintaining social connections for mental health in older people. Lancet Public Health 2020, 5, e12-e13. [CrossRef]

54. Shankar, A.; McMunn, A.; Demakakos, P.; Hamer, M.; Steptoe, A. Social isolation and loneliness: Prospective associations with functional status in older adults. Health Psychol. 2017, 36, 179-187. [CrossRef] [PubMed]

55. Suffoletto, B. Text message behavioral interventions: From here to where? Curr. Opin. Psychol. 2015, 9, 16-21. [CrossRef] [PubMed]

56. Kuerbis, A.; Van Stolk-Cooke, K.; Muench, F. An exploratory study of mobile messaging preferences by age: Middle-aged and older adults compared to younger adults. J. Rehabilitation Assist. Technol. Eng. 2017, 4, 2055668317733257. [CrossRef] [PubMed]

57. World Health Organization (WHO). WHO Strategic Communications Framework for Effective Communications. 2017. Available online: https:/ / www.who.int/mediacentre/communication-framework.pdf (accessed on 16 October 2021).

58. Frontiers in Psychiatry A Survey for Examining the Effects of COVID-19 and Infection Control Measures in Older Persons with Mild Cognitive Impairment and Dementia and Their Caregivers. 2020. Available online: https://www.frontiersin.org/articles/ 10.3389 / fpsyt.2020.599851/full (accessed on 16 October 2021).

59. Daoust, J.-F. Elderly People and Responses to COVID-19 in 27 Countries. PLoS ONE 2020, 15, e0235590. [CrossRef]

60. S\&P Global. Coronavirus Flash Survey. 2020. Available online: https://www.spglobal.com/en/research-insights/featured/ coronavirus-flash-survey-june-2020 (accessed on 16 October 2021).

61. IBM Corp. IBM SPSS Statistics for Windows, Version 27.0; Released 2020; IBM Corp: Armonk, NY, USA, 2020.

62. Brooks, S.K.; Webster, R.K.; Smith, L.E.; Woodland, L.; Wessely, S.; Greenberg, N.; Rubin, G.J. The psychological impact of quarantine and how to reduce it: Rapid review of the evidence. Lancet 2020, 395, 912-920. [CrossRef]

63. Lotoala, F.; Breheny, M.; Alpass, F.; Henricksen, A. Health and wellbeing of older Pacific Peoples in New Zealand. N. Z. Med. J. 2014, 127, 27-39.

64. Victor, C.R.; Bowling, A. A Longitudinal Analysis of Loneliness Among Older People in Great Britain. J. Psychol. 2012, 146, 313-331. [CrossRef]

65. New-Wave Homecare. The Benefits of Elderly Home Care During COVID-19. 2021. Available online: https://www. newwavehomecare.com/the-benefits-of-elderly-home-care-during-covid-19/ (accessed on 16 October 2021).

66. De Mello, M.T.; Silva, A.; Guerreiro, R.C.; da-Silva, F.R.; Esteves, A.M.; Poyares, D.; Piovezan, R.; Treptow, E.; Starling, M.; Santoro Rosa, D.; et al. Sleep and COVID-19: Considerations about immunity, pathophysiology, and treatment. J. Sleep Sci. 2020, 13, 199-209. [CrossRef] 
67. Valtorta, N.; Hanratty, B. Loneliness, isolation and the health of older adults: Do we need a new research agenda? J. R. Soc. Med. 2012, 105, 518-522. [CrossRef]

68. OECD. OECD Policy Responses to Coronavirus (COVID-19)—COVID-19: Protecting People and Societies. 2020. Available online: https:/ / www.oecd.org/coronavirus / policy-responses/covid-19-protecting-people-and-societies-e5c9de1a/ (accessed on 16 October 2021).

69. Steinman, M.A.; Perry, L.; Perissinotto, C.M. Meeting the Care Needs of Older Adults Isolated at Home During the COVID-19 Pandemic. JAMA Intern. Med. 2020, 180, 819-820. [CrossRef]

70. Eberly, L.A.; Khatana, S.A.M.; Nathan, A.S.; Snider, C.; Julien, H.M.; Deleener, M.E.; Adusumalli, S. Telemedicine Outpatient Cardiovascular Care During the COVID-19 Pandemic: Bridging or Opening the Dgital Divide? Circulation 2020, 142, 510-512. [CrossRef]

71. Eberly, L.A.; Kallan, M.J.; Julien, H.M.; Haynes, N.; Khatana, S.A.M.; Nathan, A.S.; Snider, C.; Chokshi, N.P.; Eneanya, N.D.; Takvorian, S.U.; et al. Patient Characteristics Associated with Telemedicine Access for Primary and Specialty Ambulatory Care During the COVID-19 Pandemic. JAMA Netw. Open 2020, 3, e2031640. [CrossRef]

72. Berg-Weger, M.; Morley, J.E. Loneliness and Social Isolation in Older Adults during the COVID-19 Pandemic: Implications for Gerontological Social Work. J. Nutr. Health Aging 2020, 24, 456-458. [CrossRef]

73. Jahrami, H.; Bahammam, A.S.; Bragazzi, N.L.; Saif, Z.; Faris, M.; Vitiello, M.V. Sleep problems during the COVID-19 pandemic by population: A systematic review and meta-analysis. J. Clin. Sleep Med. 2021, 17, 299-313. [CrossRef]

74. Nouri, S.; Khoong, E.C.; Lyles, C.R.; Karliner, L. Addressing Equity in Telemedicine for Chronic Disease Management During the Covid-19 Pandemic. NEJM Catalyst: Innovations in Care Delivery. 2020. Available online: https://catalyst.nejm.org/doi/full/10.1 056/CAT.20.0123 (accessed on 16 October 2021). 